\title{
Effect of Modulation of the Inlet Velocity and Equivalence Ratio Gradients on the Stabilization of Stratified Axisymmetric Bluff-Body Flames
}

\author{
G. Paterakis $\mathbb{D}$ and P. Koutmos \\ Laboratory of Applied Thermodynamics, Department of Mechanical Engineering and Aeronautics, University of Patras, \\ Patras 26500, Greece
}

Correspondence should be addressed to G. Paterakis; paterakis.gio@gmail.com

Received 29 January 2018; Accepted 17 July 2018; Published 9 August 2018

Academic Editor: Constantine D. Rakopoulos

Copyright (C) 2018 G. Paterakis and P. Koutmos. This is an open access article distributed under the Creative Commons Attribution License, which permits unrestricted use, distribution, and reproduction in any medium, provided the original work is properly cited.

\begin{abstract}
An investigation of ultralean stratified, disk stabilized, propane flames operated with acoustic modulation of the inlet velocity and fuel-air mixture profiles is presented. Transverse acoustic forcing was applied to the air, upstream of a double-cavity premixer section, formed along three concentric disks, which fueled the stabilization region with a radial mixture gradient. Measurements and supporting Large Eddy Simulations with a nine-step mechanism for propane combustion were performed to evaluate variations in the ultralean flame characteristics under forced and unforced conditions. The effects of forcing on the heat release profiles and on the interaction of the toroidal flame with the recirculation region are examined and discussed. The impact of the acoustic excitation of inlet conditions on the local extinction behavior is, also, assessed by monitoring a local stability criterion and by analyzing phase-resolved chemiluminescence images.
\end{abstract}

\section{Introduction}

In the design of fuel flexible, low emissions, versatile combustion systems, the lean premixed operating mode has been effectively exploited in a range of applications [1]. Recently combustion technology based on partially premixing or stratifying the reactive mixture has emerged as an equally promising methodology in the effort to optimize and expand further the operational margin of the lean fully premixed concept [2-6].

However, with ultralean flame operation under both modes of combustion, instabilities that can affect the burner performance remain a challenge in the further development of current systems $[5,7]$. The study of the impact of modulation (acoustic or not) of the fuel or air supplies on critical flame properties represents a useful diagnostic methodology in the effort to understand the interaction and correlation of these instabilities with burner operation and determine their effect on system performance [5].

Several works have addressed the effects of acoustic velocity excitations or fuel mixture perturbations on the flow-field-flame interactions and have established the response of significant properties of the reacting system with the prospect of devising general purpose transfer functions for use in the design process. Other works have exploited modulation of the main fuel supply to actively control and improve the operating envelope close to the lean limit [8].

Mixture stratification and/or incomplete premixing are also increasingly encountered in ultralean combustors, either as an attractive option to manage mixture placement or as a result of undesirable conditions due to limiting operation $[6,9-11]$.

Recently a number of investigations have highlighted the considerable impact of the inlet mixture stratification and the particular stabilization configuration on the dynamic flame response under a combined modulation of the equivalence ratio and the inlet velocity profile $[8,9,11]$.

Further investigations of the response of partially premixed flames to different types of inlet velocity or mixture disturbances of varying amplitude and frequency under a variety of premixing arrangements, stabilizing geometries, and mixture conditions seem therefore warranted and this 
represents a motivation for the present study. The response of flames operated near their lean blow-out limit is also a further aspect addressed in the present study.

The work describes an initial effort to investigate the characteristics of stratified propane flames, formed through partial fuel-air premixing within a three-disk double-cavity arrangement, stabilized at the afterbody disk and operated with periodic forcing of the velocity profile at the inlet to the premixing section.

The application of acoustic forcing of the inlet air supply upstream of the double-cavity premixer introduces perturbations to both velocity and equivalence ratio profiles entering the flame stabilization region. Operated under the present conditions, the cavity system, as discussed below, propagates the velocity modulation with little distortion, while it produces an equivalence ratio oscillation with a phase and amplitude variation with respect to the velocity perturbations entering the combustion zone. This introduces a further significant complexity that is sometimes found in burner applications and adds to the practical significance of the investigated setup [7].

Previous works (e.g., [11, 12]) have emphasized the considerable influence of the variations in the velocity and mixture perturbations fed into the combustion zone for premixed and partially premixed configurations. In these works, equivalence ratio oscillations mostly with amplitudes smaller than the inlet velocity oscillation amplitude [11, 12] were studied. In the present cavity setup the levels of the inlet velocity forcing are combined with a variable range of equivalence ratio perturbation amplitudes produced by the premixer. The impact of these combinations on the flame characteristics is examined below. Within this initial effort, lean and ultralean flames operated near the blow-off limit were chosen for evaluation by performing experiments and supporting simulations under forced and unforced inlet conditions.

\section{Experimental Setup and Methods}

Premixer/Burner Configuration. The combustion tunnel and the burner geometry described below in detail are similar to those reported also in $[3,13]$ and a schematic layout of the experimental setup is provided in Figure 1. The premixer/burner system was composed of three concentric axisymmetric disks connected along their axis with a vertical hollow tube, namely, a forebody disk (C), a hollow fuel injecting disk (B in Figure 1), and the flame stabilizing afterbody $(A)\left(D_{b}=0.025 \mathrm{~m}\right)$. Propane was supplied along the central connecting tube and was injected through an annular slot into the primary fuel-air mixing cavity. The second cavity, designed to operate without flashback, promoted further premixing prior to ignition and flame stabilization in the downstream afterbody recirculation. The three-disk/double-cavity system was placed within a containing pipe $\left(D_{c}=0.052 \mathrm{~m}\right)$. A range of stratified flames with variable equivalence ratio gradients could be anchored at the afterbody recirculation region close to the exit plane of the premixer system. The blockage ratio at the premixer afterbody exit plane system was $\left(\mathrm{BR}=\left(\mathrm{D}_{\mathrm{b}} / \mathrm{D}_{\mathrm{c}}{ }^{2}\right)=0.23\right.$. The Reynolds number $\left(\mathrm{U}_{0} \mathrm{D}_{\mathrm{b}} / \nu\right)$ was maintained at 8000 . The near reacting wake region was confined by a cylindrical pipe of $104 \mathrm{~mm}$ diameter extending $100 \mathrm{~mm}$ downstream from the premixer exit plane. This provided optical access and shielding from the surrounding environment air. Acoustic pressure measurements were monitored along the central containing tube and the confining pipe. Velocity oscillations were applied at the premixer inlet, with two loudspeakers oppositely mounted on the circumference of the air supplying central tube, at a plane $6 \mathrm{D}_{c}$ upstream of the primary injecting cavity. The loudspeakers were excited by a sinusoidal signal generated by using an arbitrary waveform generator. The downstream double-cavity premixer system produced a modulation of the equivalence ratio profiles entering the flame stabilization region with a phase and amplitude difference that depended on the inlet air perturbation, the acoustics of the cavity system, and the turbulent mixing. In the present case the mixture perturbations at inlet to the afterbody flame zone were independent of the choked fuel injector impedance. Although the experimental setup can be operated under external swirl, the present study was confided to nonswirling conditions. Under forced conditions peripheral flow symmetry was monitored through circumferentially placed pressure taps, close to the premixer outlet, and nonuniformities were seen to be maintained below a deviation of $1.7 \%$.

The main air was supplied to the experimental rig through an inhouse constructed orifice plate according to ISO regulations with $2.5 \%$ uncertainty. The propane flow was regulated by a Bronkhorst MV-304 Hi-Tech mass flow controller with uncertainty $1.25 \%$ of FSD (Full-Scale Deflection). An illustration of the previously simulated time-mean flow patterns within this cavity system without forcing, together with the air supply and primary fuel injection position, is depicted in Figure 2 [3].

The unforced equivalence ratio gradient at the afterbody exit attained values of $\Phi_{\min } / \Phi_{\max } \approx 0.16 / 0.95$ and $0.10 / 0.70$ for lean and ultralean flame conditions (Figure 2), as measured with a Fourier Transform Infrared Spectroscopy (FTIR, Spectrum Two ${ }^{\mathrm{TM}}$ spectroscopy analyzer, PerkinElmer ${ }^{\circledR}$ ) by analysis of locally collected gas samples. A stratified reactive mixture profile was maintained across the most favourable position for leading edge flame front stabilization, i.e., at the afterbody rim region. The flame proximity to the lean blow-off (LBO) limit, denoted by the parameter, $\delta=\left(\mathrm{m}_{\mathrm{f}}\right.$ $\left.\mathrm{m}_{\mathrm{f}, \mathrm{LBO}}\right) / \mathrm{m}_{\mathrm{f}, \mathrm{LBO}}$, was $8.5 \%$ for the ultralean flame, where inlet acoustic air forcing studies were focused.

2.1. Measurement Techniques. Pressure transducers and Hot Wire Anemometry (HWA) were used to obtain the pressure and velocity perturbation signals at the premixer inlet and at the afterbody exit region.

Chemiluminescence (CL) images of $\mathrm{OH}^{*}$ are frequently employed to identify the topology of the flame front [2]. CL images were taken with a LaVision ${ }^{\circledR}$ FlameMaster ${ }^{\circledR}$ imaging system comprising an Elite 2M CCD camera, an image intensifier IRO unit, optical filters, and lenses for $\mathrm{OH}^{*}$ imaging. Specifically, image acquisition and data 

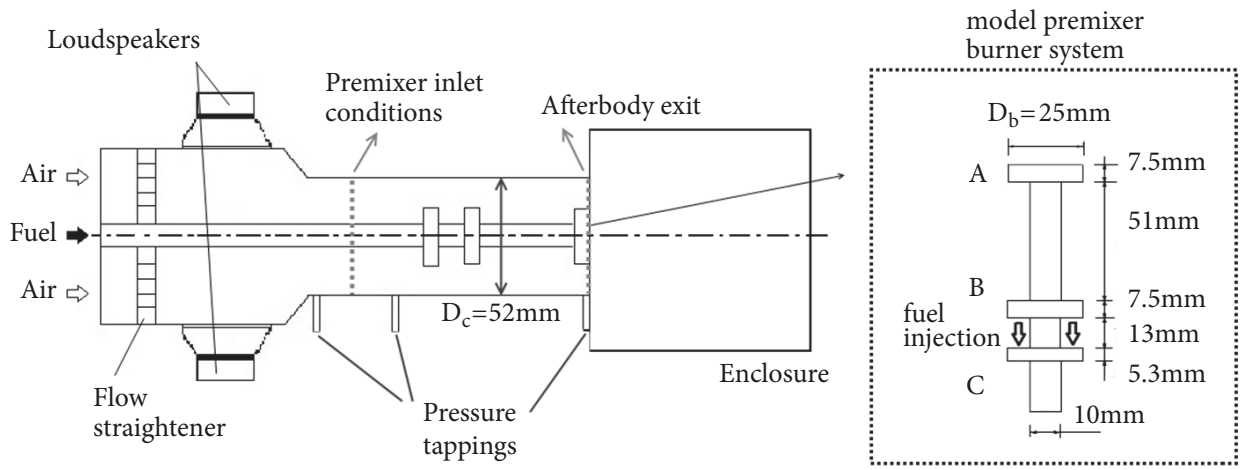

FIGURE 1: Combustion tunnel and model premixer/burner system.

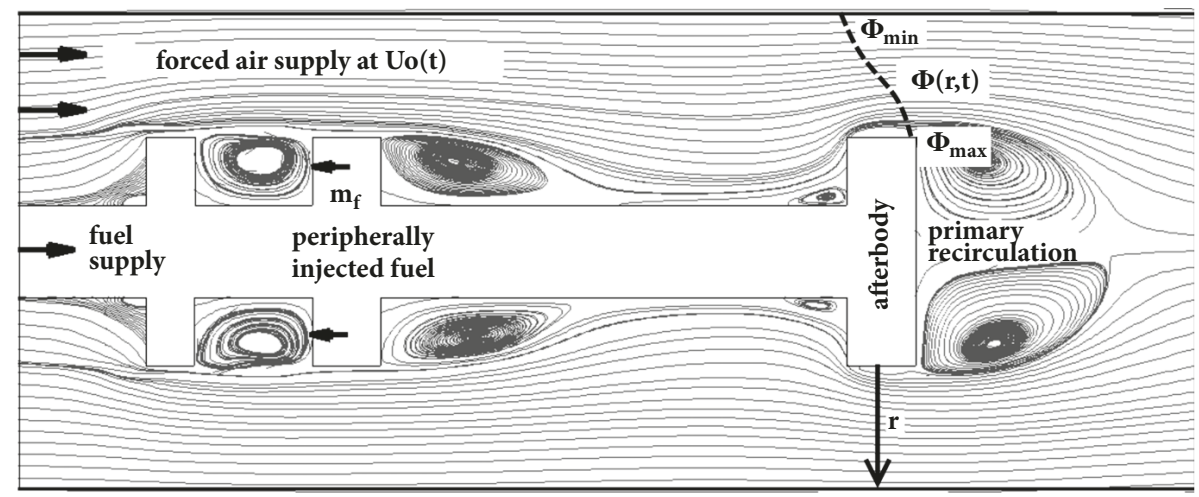

FIgURE 2: Flow patterns, fuel-air placement within the premixing cavities, and mixture stratification at the afterbody exit plane.

reduction were performed using the Davis $8.0^{\circledR}$ software $\left(\right.$ LaVision $\left.^{\circledR}\right)$. The background images, taken under the same integration time and gain as the flame images, were then subtracted from the originals similar to [13]. For phaseaveraged imaging, the CCD camera was synchronized with the inlet pressure signal and 100 instantaneous images, at a maximum interrogation window $(1626 \times 1236$ pixels $)$, were taken repeatedly at predetermined phase-angles $\left(0^{\circ}, 90^{\circ}\right.$, $180^{\circ}$, and $\left.270^{\circ}\right) ; \theta=0^{\circ}$ corresponds to the negative-to-positive reference signal transition and $\theta=90^{\circ}$ to its peak value. The signal-to-noise ratio of the instantaneous images was better than 5:1 and the exposure time was $2.1 \mathrm{~ms}$. Moreover, intensifier gate times of the order of $100 \mu$ s were used for the measurements with a gain at $75 \%$, analogous to [13].

A microprobe was used to collect gas samples at the afterbody exit, under plane mixing conditions. The collected gas samples were fed into a volume gas cell and were analyzed via a Fourier Transform Infrared Spectroscopy (FTIR, Spectrum Two spectroscopy analyzer, PerkinElmer), using Spectrum $10^{\circledR}$ software.

The spectrum analysis of each sample was performed in the range 450 to $4000 \mathrm{~cm}^{-1}$, with $0.5 \mathrm{~cm}^{-1}$ resolution, and was correlated with a calibration curve to allow estimation of the corresponding fuel-air concentration with an accuracy up to $8 \%[14]$.
The resonant frequencies of the combustor configuration were found to be around 129,209 , and $351 \mathrm{~Hz}$; for this study forcing frequencies of $50,100,200$, and $300 \mathrm{~Hz}$ were considered. Data were obtained with forcing amplitude (peakto-peak voltage to the speakers) at the air inlet of $20 \%$ of the mean velocity (half peak-to-peak amplitude of velocity oscillation to the bulk velocity) and the forcing frequency could be varied between 50 and $400 \mathrm{~Hz}$. The fundamental frequency of the downstream enclosure was determined at near $1 \mathrm{kHz}$.

\section{Numerical Models and Solution Procedure}

All the simulations of the studied flames were performed with Ansys 17.0 (Ansys Inc.). The commercial software allowed straightforward mesh adaption flexibility within the premixer sections, in the annular slot on the backward face of the second disk, where fuel was introduced into the primary cavity and in the $7.5 \mathrm{~mm}$ annular rim region, where the peak levels of the equivalence ratio gradient promote flame stabilization at the afterbody recirculation region.

A Large Eddy Simulation approach was employed here to capture the transient turbulent processes involved in the forced reacting wakes. The flow variables, F, were expressed 
as resolvable $\widetilde{F}$ and subgrid, $F^{\prime}$, level quantities using a Favreweighted filter, $\widetilde{F}=\overline{\rho F} / \bar{\rho}$. The resolved scale flow quantities are described by the following equations $[10,13,15,16]$ :

continuity is

$$
\frac{\partial \bar{\rho}}{\partial t}+\frac{\partial\left(\bar{\rho} \widetilde{u}_{i}\right)}{\partial x_{i}}=0
$$

momentum is

$$
\begin{aligned}
\frac{\partial \bar{\rho} \tilde{u}_{i}}{\partial t}+\frac{\partial\left(\bar{\rho} \tilde{u}_{i} \tilde{u}_{j}\right)}{\partial x_{j}}= & -\frac{\partial \bar{p}}{\partial x_{i}}+\frac{\partial}{\partial x_{j}}\left[\mu\left(\frac{\partial \tilde{u}_{i}}{\partial x_{j}}+\frac{\partial \widetilde{u}_{j}}{\partial x_{i}}\right)\right] \\
& -\frac{\partial \tau_{i j}^{a}}{\partial x_{j}}+\left(\Delta \bar{\rho}_{\infty}\right) g_{i}
\end{aligned}
$$

and scalars are

$$
\begin{array}{r}
\frac{\partial \bar{\rho} \tilde{Y}_{k}}{\partial t}+\frac{\partial\left(\bar{\rho} \tilde{u}_{j} \tilde{Y}_{k}\right)}{\partial x_{j}}=\frac{\partial}{\partial x_{l}}\left(\bar{\rho} D_{k} \frac{\partial \widetilde{Y}_{k}}{\partial x_{l}}\right)-\frac{\partial J_{l}}{\partial x_{l}}+\bar{\rho}_{\tilde{\dot{\omega}}_{Y_{k}}} \\
k=1, N
\end{array}
$$

An energy equation is also solved to yield the variation of the local temperature in the above system. The variables $\rho$, $\mu, \mathrm{T}, \mathrm{u}_{\mathrm{i}}$, and $\mathrm{Y}_{\mathrm{k}}$ represent the density, viscosity, temperature, velocity, and the gaseous species mass fractions. In the tensorial notation used above $\mathrm{i}=1,2,3$ in a Cartesian system $(\mathrm{x}, \mathrm{y}, \mathrm{z})) \cdot \tau_{i j}^{\alpha}=\tau_{i j}-1 / 3 \tau_{i j} \delta_{i j}$ is the anisotropic part of the subgrid stress tensor, $\tau_{i j}$, with the isotropic part of the viscous and subgrid stress being adsorbed into the pressure. A subgrid eddy viscosity is used to model the subgrid scale stresses as $\tau_{i j}^{\alpha}=-2 \mu_{t, s g s} \widetilde{S}_{i j}$, where $\mu_{s g s}=\tilde{\rho}\left(C_{s} \bar{\Delta}\right)^{2}\left(2 \widetilde{S}_{i j} \widetilde{S}_{i j}\right)^{1 / 2}$, $\widetilde{S}_{i j}$ is the resolved scale strain tensor, and $\Delta$ is the filter width, which for the finite-volume approach employed here is assumed proportional to the local mesh spacing, $\Delta=$ $\sqrt[3]{\Delta x_{i} \Delta y_{i} \Delta z_{i}}$. A gradient hypothesis is used for the evaluation of the subgrid scale scalar flux as follows: $J_{k}=\bar{\rho}\left(\widetilde{u_{l} Y_{k}}-\widetilde{u}_{l} \widetilde{Y}_{k}\right)=$ $-\left(\mu_{t, s g s} / S c_{t, s g s}\right)\left(\widetilde{Y}_{k} / x_{l}\right)$, where a turbulent subgrid Schmidt number, $\mathrm{Sc}_{\mathrm{t}, \mathrm{sgs}}$, of 0.7 is assumed. Turbulent transport is modelled with the dynamic Smagorinsky model embodied in the basic software $[6,10,11]$ with the dynamic Smagorinsky coefficient $\mathrm{C}_{s}$ in the sgs eddy viscosity constrained for stability between 0 and 0.23 . A time-dependent SIMPLE algorithm [10, 15] was employed to treat pressure-velocity coupling. Time discretization was obtained with a secondorder accurate scheme, and the time step was chosen to maintain a maximum Courant number between 0.4 and 0.6.

Time-series data were collected over 2000 time steps and relevant statistics were obtained from the resolved scale quantities while the contributions from the subgrid scale stresses were also included. The simple $\mathrm{P}-1$ radiation model available in the software (Ansys Inc.) was adopted in the present simulations (although temperature measurements were not corrected for radiation its adoption in the simulations is likely to allow more flexibility in future processing of the present data).
3.1. Combustion Model. The Thickened Flame model (TFM) $[17,18]$ was employed here to describe the range of combustion regimes that may result from the various limiting fuel settings. This formulation was coupled to a nine-step reduced scheme for propane (i.e., $R x n$ 1: $\mathrm{C}_{3} \mathrm{H}_{8}+\mathrm{O}_{2}+\mathrm{OH}+\mathrm{H} \longrightarrow$ $3 \mathrm{CO}+5 \mathrm{H}_{2}$, Rxn 2: $\mathrm{CO}+\mathrm{OH} \longleftrightarrow \mathrm{CO}_{2}+\mathrm{H}$, Rxn $3: 3 \mathrm{H}_{2}+\mathrm{O}_{2} \longleftrightarrow$ $2 \mathrm{H}_{2} \mathrm{O}+2 \mathrm{H}, \mathrm{Rxn} 4: 2 \mathrm{H}+\mathrm{M} \longrightarrow \mathrm{H}_{2}, R x n 5: \mathrm{H}_{2}+\mathrm{O}_{2} \longleftrightarrow 2 \mathrm{OH}$, Rxn 6: $\mathrm{C}_{3} \mathrm{H}_{8}+\mathrm{O}+\mathrm{OH}+\mathrm{H} \longrightarrow \mathrm{C}_{2} \mathrm{H}_{2}+\mathrm{CO}+\mathrm{H}_{2} \mathrm{O}+3 \mathrm{H}_{2}, R x n$ 7: $\mathrm{C}_{2} \mathrm{H}_{2}+\mathrm{O}_{2} \longleftrightarrow 2 \mathrm{CO}+\mathrm{H}_{2}, R x n 8: 2 \mathrm{O}+\mathrm{M} \longleftrightarrow \mathrm{O}_{2}$, and $R x n$ 9: $\left.\mathrm{O}_{2}+\mathrm{H} \longleftrightarrow \mathrm{O}+\mathrm{OH}\right)$. This has been tuned to reproduce well the flame speed over the lean $\Phi$ range and represents an extension of the mechanism described in [19], now including the radical $\mathrm{OH}$ to facilitate indirect comparisons with the measured $\mathrm{OH}^{*}$ topologies.. It should be remarked that although all the species are explicitly solved for on the computational grid it is likely that fast radicals may not be resolved appropriately within the present level of refinement. In the present moderate Reynolds number laboratory flames, the exploitation of the above combination of turbulence models and chemistry scheme can be considered attractive, in providing a more detailed and extensive description of the developing flame front properties, while at the same time allowing for a more direct comparison with experimental imaging results, e.g., chemiluminescence.

The averaged source terms involving reaction rates were calculated with the help of the ISAT algorithm available in the software [10]. Measurements reported in [3] have suggested that the lean flames lie in the thin reaction regime. The present ultralean flames may be a borderline case and closer to the broken reaction zone boundary with computed Karlovitz numbers [1] $\left(\mathrm{Ka}=\tau_{\mathrm{ch}} / \tau_{\mathrm{k}}\right.$, where $\tau_{\mathrm{ch}}$ and $\tau_{\mathrm{k}}$ are the chemical and Kolmogorov timescales) of about 80 and estimated local grid based Karlovitz numbers of even higher values. An effort was also made to examine the response of the localized extinction behavior with respect to the imposed inlet perturbations in the simulations. The ratio of the local Karlovitz number to the Karlovitz stretch factor, $\mathrm{Ka}_{\text {ex }}$, as defined for symmetric counterflow laminar flame extinction (this being a function of the local $\Phi$ (e.g., [1])), was monitored in the temperature shear layer flanking the toroidal recirculation. Extinction was determined whenever the parameter $\Lambda=\mathrm{Ka} / \mathrm{Ka}_{\mathrm{ex}}$ attained values greater than 1 .

3.2. Computational Details. Mesh refinement and systematic adaption were performed in the primary fuel injector cavity, near the disk walls and at the fuel-air shear layer emanating from the annular afterbody plane, where flame front stabilization is achieved.

The simulation domain included the complete multicavity premixer section with the inlet placed upstream of the first disk. Within the context of the software and the available computational resources a hybrid mesh system was used. It was unstructured and denser in the symmetry axis to alleviate convergence problems in the present axisymmetric configuration, in the fuel injection annular slot region to allow for a correct fuel-air distribution and it was structured in other locations. Between 0.87 and 1.38 Mcells were employed in the grid refinement studies and the finer mesh 
was used for the final runs. No-slip boundary conditions were used near walls with the node close to the disk walls placed at $\Delta y / D_{b}=0.00175$, while the law of the wall was applied elsewhere. Inlet conditions were taken from measurements, while a convective condition was applied at the exit. The quality of the present LES was examined by calculating the resolved fraction of the turbulence energy, $\mathrm{R}_{\mathrm{k}}=\mathrm{k}_{\mathrm{res}} /\left(\mathrm{k}_{\text {res }}\right.$ $+\mathrm{k}_{\mathrm{sgs}}$ ), which achieved values up to $90 \%$ within the main reaction zone.

After obtaining a statistically steady flow solution, the inlet air velocity boundary condition was excited with a harmonic wave of fixed amplitude. The amplitude (being the ratio of half peak-to-peak amplitude of velocity oscillation at harmonic forcing frequency to the bulk velocity) was kept constant at $20 \%$ over the experimentally studied range of frequencies. The approach of [15] was followed to apply consistent boundary conditions within the context of the employed software.

Computational times on (48) processors (4 XEON 5660, $2.83 \mathrm{GHz})$ run in parallel were about $3.7 \mathrm{CPU}$ hrs for the simulation of one flow-through time $\left(\tau=\mathrm{D}_{\mathrm{b}} / \mathrm{U}_{0}=5 \times 10^{-3} \mathrm{~s}\right)$. Time series of various investigated quantities were gathered for about $225 \tau$ and relevant statistics were obtained by postprocessing this sample.

\section{Results and Discussion}

The characteristics of the unforced, "base case," flame influence the particular response behavior at each level of forcing [9]. The simulated temperature and heat release distributions, for the presently studied ultralean setup and the counterpart lean case, are compared in Figure 3 and denote the character of the chosen limiting flame.

The conical shape of the lean flame becomes cylindrical under ultralean operation, while the leading edge of the reacting front stabilizes at a lift-off distance from the disk. This disposition is similar to that found in various studies of stratified bluff-body flame stabilization [2]. The flame shapes are also consistent with the present inlet radial mixture profile, whereby richer levels of the equivalence ratio are sustained closer to the afterbody rim wall (Figure 2). This topology is verified by the measured $\mathrm{OH} *$ chemiluminescence distributions and the accompanying $\mathrm{OH}$ simulations displayed in Figure 3.

A three-point Abel deconvolution scheme was used to extract 2D information from the line-of-sight integrated experimental $\mathrm{OH} *$ images [20]. The placement of the lean and ultralean flame disposition illustrated in Figure 3 clearly indicates that the limiting reacting configuration chosen as a reference for the present study indeed represents a weaker flame topology, closer to LBO topology, in terms of anchoring position and stability, when compared to previous robust flame configurations used for modulation studies [21]. Comparisons between measurements and simulations of detailed velocity and temperature fields reported in [3] have suggested that the variations in the transition from lean to ultralean flame behavior were followed adequately by the simulation methodology and this lends some initial

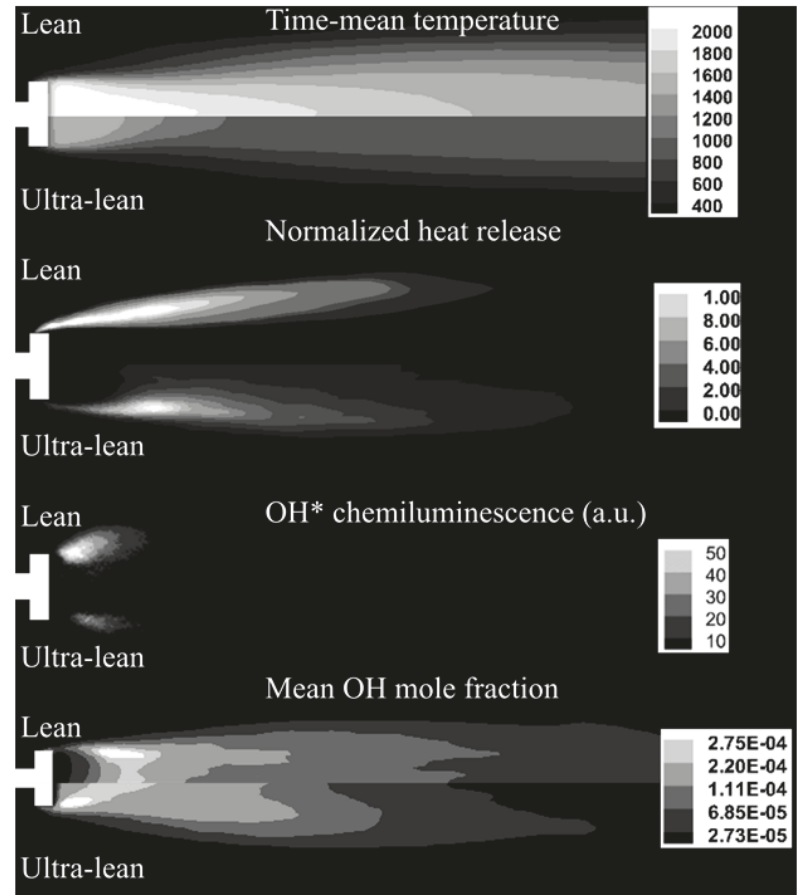

FIGURE 3: Unforced base flame topology and characteristics.

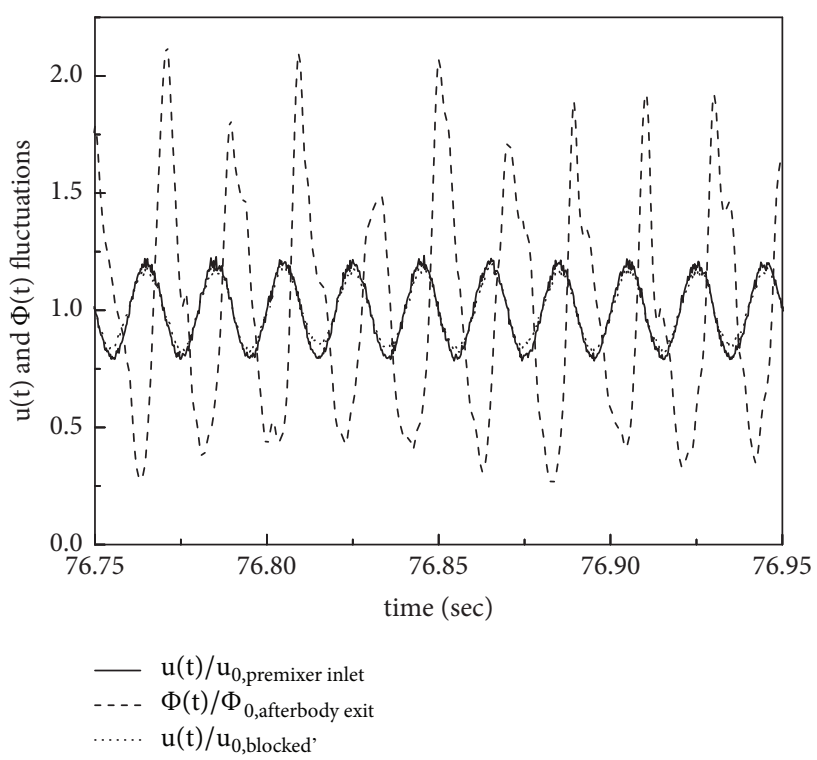

FIGURE 4: Computed velocity and equivalence ratio fluctuations at premixer inlet and afterbody exit.

credibility for extending the basic approach to investigate the forced flames configurations.

The dynamic behavior of the burner crucially depends on the inlet velocity and mixture profiles that enter the combustion zone from the afterbody annular exit gap. Figure 4 shows the harmonically forced area-weighted inlet velocity, at $50 \mathrm{~Hz}$, given as boundary condition at the premixer inlet.

This figure shows also the resulting variation of the velocity and equivalence ratio values at the afterbody exit and 


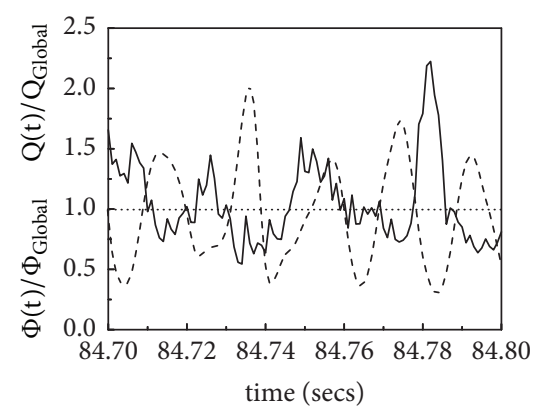

- - $\Phi$ afterbody exit Q, $50 \mathrm{~Hz}$

(a)

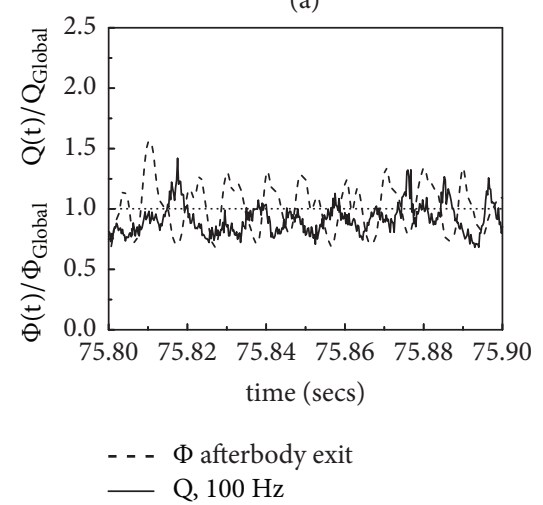

(b)

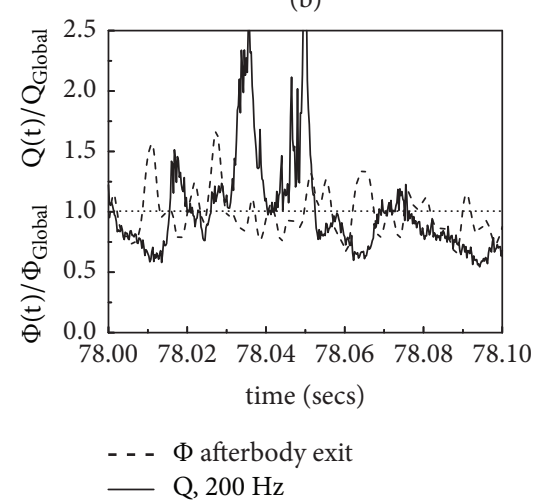

(c)

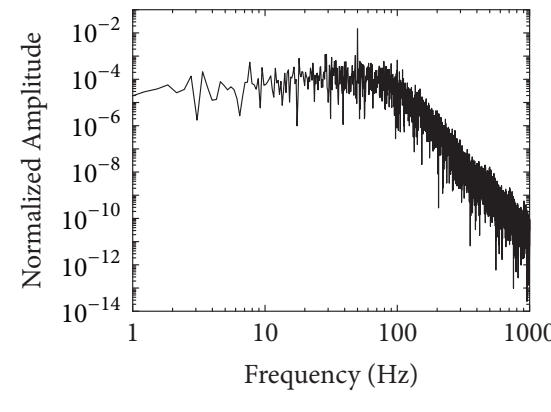

$50 \mathrm{~Hz}-\Phi$

(d)

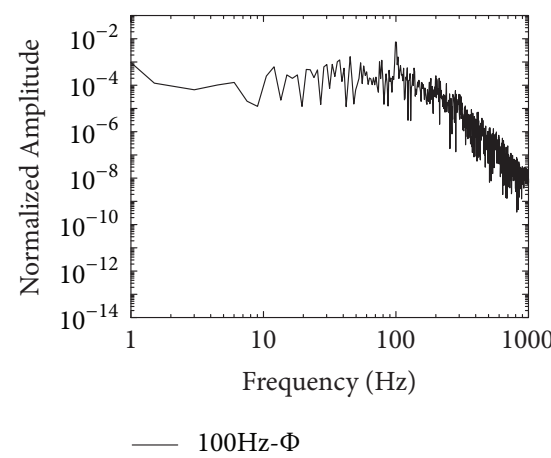

(e)

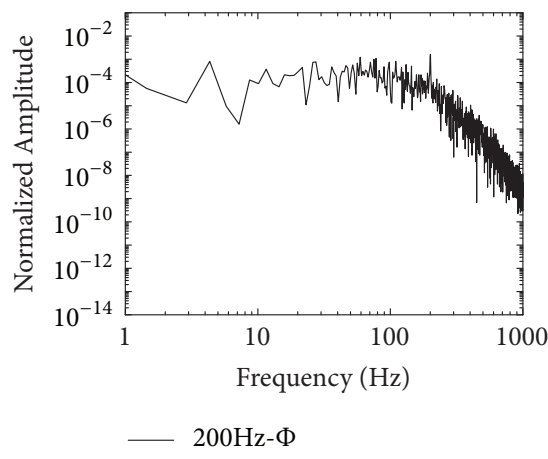

(f)

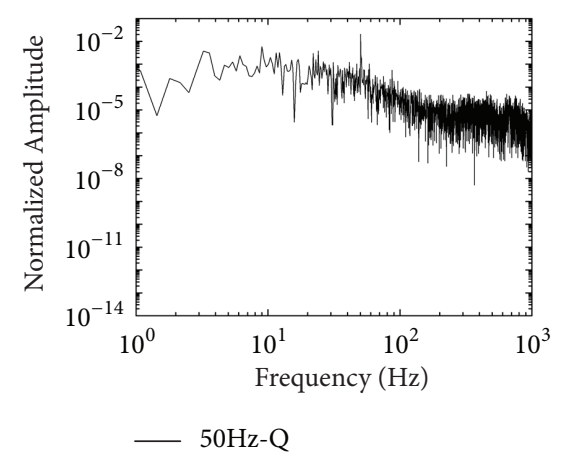

(g)

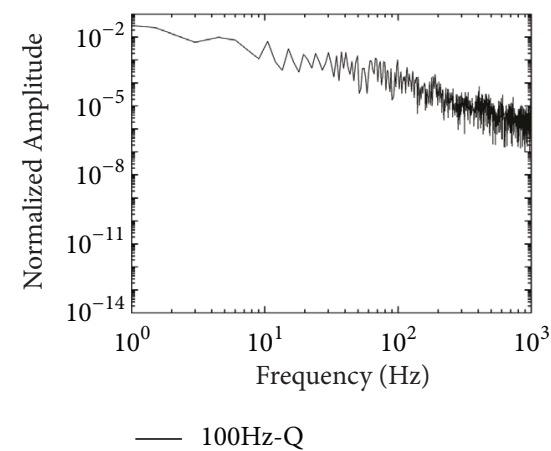

(h)

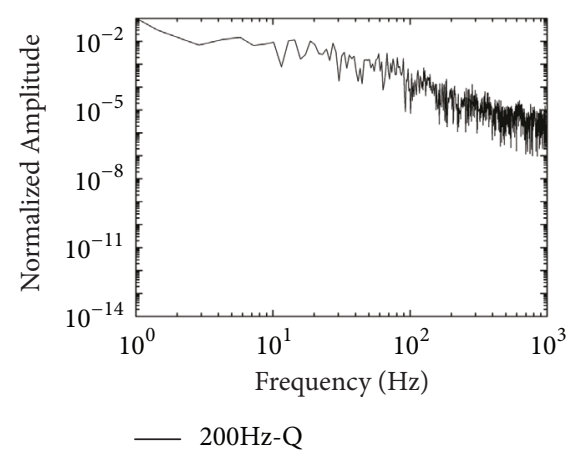

(i)

FIGURE 5: Simulated volume integrated, flame zone heat release $(\mathrm{Q})$ and afterbody exit, and area-weighted equivalence ratio $(\Phi)$ time series together with their respective spectral densities at the three forcing frequencies of (a, d, g) $50 \mathrm{~Hz},(\mathrm{~b}, \mathrm{e}, \mathrm{h}) 100 \mathrm{~Hz}$, and $(\mathrm{c}, \mathrm{f}, \mathrm{i}) 200 \mathrm{~Hz}$.

emphasizes the differences in the resulting modulation levels of these two signals due to the broadening effect through the cavity premixer. The observed $\Phi$ oscillation at the afterbody exit is attenuated as the fuel is injected, convected, and mixed with the central airflow downstream from the primary cavity fuel injection position towards the flame front anchoring location. $\Phi$ fluctuates as it enters the reaction zone with a phase difference of about $180^{\circ}$ with respect to the afterbody exit velocity.

It is evident that although the distortion in the velocity signal through the premixer is only quite moderate (a situation maintained for all forcing frequencies), the equivalence ratio fluctuations are more drastically affected in terms of both magnitude and phase. The distortion seen between the premixer inlet velocity and the afterbody exit $\Phi$ signal at $50 \mathrm{~Hz}$ can be considered the result of the interaction of the perturbed in-cavity flow with the fuel injection leading to a phase shift of $180^{\circ}$ and an amplitude deviation of more than $100 \%$. The effect of the premixer section on the afterbody exit $\Phi$ modulation varies with frequency forcing, as demonstrated below in the heat release profiles; this combination yields modulations of both the velocity and mixture gradients at inlet to the main reaction zone, with variable frequency content and amplitude in a fashion that is different from previously reported studies $[11,21]$. 
Figures 5(a), 5(b), and 5(c) display the variation of the volume integrated, flame zone heat release profile with time, for modulation levels of 50,100 , and $200 \mathrm{~Hz}$, together with the corresponding afterbody exit, and area-weighted equivalence ratio fluctuations as obtained from the simulations. Additionally, Figures 5(d), 5(e), and 5(f) and Figures 5(g), 5(h), and 5 (i) depict the spectral behavior of the above $\Phi$ and $Q$ values, respectively, at the same forcing frequency conditions.

At the lower frequency of $50 \mathrm{~Hz}$ the overshoots in heat release response are significant and exhibit a phase difference of around $180^{\circ}$ with respect to the equivalence ratio fluctuations; the significant portion of signal excursions above and below the mean level imply a more disrupted character for this flame under the low forcing condition.

In contrast, the accumulation of heat release values with lower amplitude closer to the mean, in line with the incoming mixture variations, obtained at the frequency of $100 \mathrm{~Hz}$ (Figure 5(b)), is consistent with a more integrated and compact flame topology. At the higher frequency of $200 \mathrm{~Hz}$, Figure 5(c), the flame exhibits much steeper overshoots, while also attaining a significant extent of values below the mean. The distributions of the heat release here are indicative of a nonlinear response to the inlet equivalence ratio profiles. This is not surprising, since this forcing frequency is close to one of the resonant frequencies of the premixing duct/combustion zone configuration. Figure 5 also shows that the amplitude of $\Phi$ oscillation at forcing frequencies of 100 and $200 \mathrm{~Hz}$ is lower than that at $50 \mathrm{~Hz}$.

The above trends are to some extent corroborated by the corresponding spectra for the afterbody exit equivalence ratio and the integrated heat release variation, shown in Figure 5. The $\Phi$ spectra in all cases are evidently dominated by the respective forcing frequencies. The heat release spectral distribution at $50 \mathrm{~Hz}$ is also closely correlated to the modulated $\Phi$ distribution. At $100 \mathrm{~Hz}$ a more distributed spectral energy distribution is obtained across the frequency range, while at $200 \mathrm{~Hz}$ the spectral pattern that emerges appears more complex and now involves a number of elevations of lower energy over a broader frequency range. The trends depicted in these spectra are in line with the previous discussion on the evolution of the time-series profiles.

A somewhat similar behavior has also been observed experimentally in reported studies of forced partially premixed flames (e.g., [11]). In the present case this may be attributed to the influence of the oscillation frequency on the large scale mixing process within the cavity system. The higher flame sensitivity to the lower frequency modulation could be the result of the higher amplitude equivalence ratio oscillations. These may have provoked mixture concentrations closer to the extinction limits either locally or even globally, with a consequent decrease in the corresponding heat release. For this ultralean, semidetached from the burner rim flame, the lower frequency could also produce locally extinguished gas samples over longer periods of time and this could certainly have a disruptive effect on the integrity and continuity of the flame front. The results tentatively confirm similar findings from previously reported works (e.g., $[8,12])$ and concur that at this lower frequency modulation the response of the heat release is rather due to the cycle variation

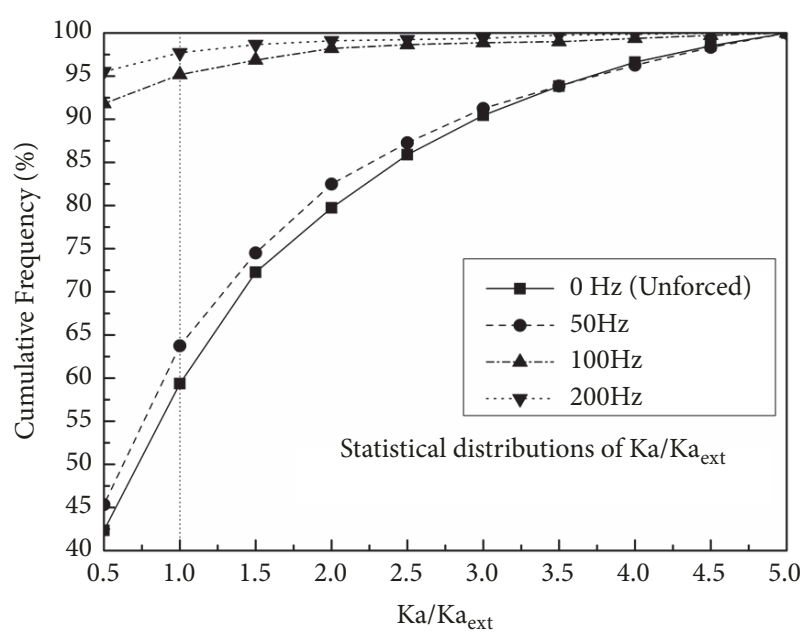

FIGURE 6: Cumulative frequency distributions of the normalized Karlovitz number at the investigated frequencies.

in the inlet equivalence ratio and not due to flame surface modulation and vortex interactions.

The computed Karlovitz ratio, extinction parameter, $\Lambda$, was monitored at a position located within the recirculation region and close to the reacting flame front $\left(\left(\mathrm{x}, \mathrm{r} / \mathrm{D}_{\mathrm{b}}\right)=(0.4\right.$, $0.4)$ ), which is critical for flame stabilization, at least for the topology of the base case flame.

Cumulative frequency analysis has been performed to provide insight into the probability of an individual value of the normalized extinction parameter, $\Lambda$, to exceed the given threshold of 1 .

The cumulative frequency of the $\Lambda$ parameter is shown in Figure 6 for forced and unforced cases, respectively, over the range of $\mathrm{Ka} / \mathrm{Ka}_{\text {ex }}$ values between 0.5 and 5 . Occurrence of localized extinction is indicated for values above 1. In this graph, $\Lambda$ values are depicted on the horizontal axis and the cumulative frequency percentage on the vertical one. The plots suggest that the resulting computed probabilities for the $\Lambda$ parameter to exceed this critical value are $59 \%, 64 \%, 95 \%$, and $98 \%$ for the unforced and the $50 \mathrm{~Hz}, 100 \mathrm{~Hz}$, and $200 \mathrm{~Hz}$ forced cases, respectively.

The distributions (as well as the corresponding scatterplots, not shown for brevity) indicate an increase of the local extinction events by more than $50 \%$ for all frequency modulations, at least for the selected monitoring point.

Interestingly, the probability of extinction events is seen to be greatly augmented at the forcing frequencies of 100 and $200 \mathrm{~Hz}$, by comparison to the lesser impact of the $50 \mathrm{~Hz}$ frequency modulation, where the distribution remains relatively close to the unforced case. This signifies that as we move from the 50 to the $100 \mathrm{~Hz}$ level of modulation a disproportionately large impact to the probability of extinction is obtained across this particular frequency gap. Therefore, the studied range of frequency modulations is clearly observed to produce a weaker effect and variation on the local flame extinction behavior, across the ranges from 0 to $50 \mathrm{~Hz}$ and from 100 to $200 \mathrm{~Hz}$. On the other hand, this effect appears 


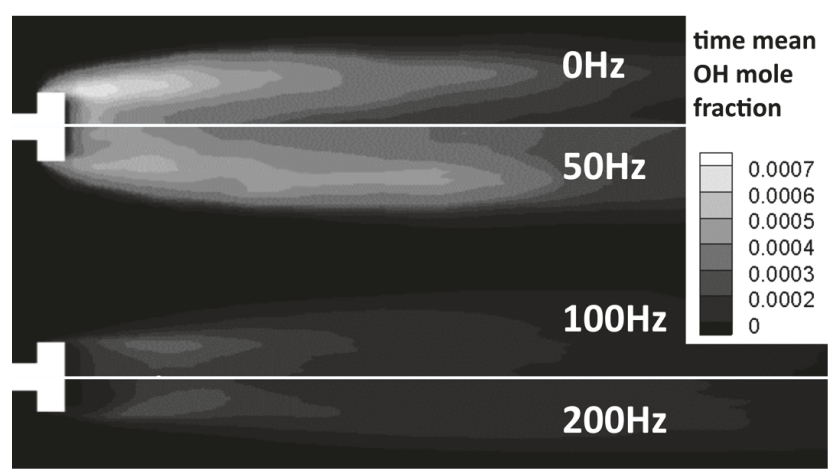

Figure 7: Computed time-mean $\mathrm{OH}$ mole fraction fields for forced and unforced flame configurations.

particularly pronounced between 50 and $100 \mathrm{~Hz}$ and this nonlinear behavior warrants further investigations.

The discernible amplification of the impact of the modulation at the forcing frequency of $100 \mathrm{~Hz}$ can be associated with a disrupted flame topology obtained at this level of modulation, as discussed below in the presentation of the phase-resolved $\mathrm{OH}^{*}$ images. On the other hand, at $50 \mathrm{~Hz}$ the close correlations between the frequencies content of the premixer outlet $\Phi$ modulation and the integrated heat release, Q, suggest a "lock-on" effect of the flame front disposition with the premixer inlet velocity and mixture profile modulation [11].

The placement in time of the toroidal flame sheet of course varies with forcing frequency and the overall stability behavior should be assessed from other monitoring positions as well or through a spatial distribution of, e.g., the $\mathrm{OH} *$ fields in each case.

This is interrelated with the disrupted flame obtained closer to the burner face at this modulation, which is also discernible in the experimentally obtained phase-resolved images shown in Figure 8.

The computed time-mean $\mathrm{OH}$ mole fraction fields are displayed for the forced and unforced configurations in Figure 7. These distributions suggest that the flames at the $200 \mathrm{~Hz}$ and $100 \mathrm{~Hz}$ forcing conditions were visibly weakened in both extent and intensity. At the $50 \mathrm{~Hz}$ level of perturbation, at least for the $20 \%$ amplitude, the flame maintains its intensity and it is withdrawn upstream, closer to the rim and face of the disk stabilizer, while the reacting front exhibits higher levels of $\mathrm{OH}$ with respect to the base flame. This trend is supported by the phase-averaged measurements discussed below. Such phase-resolved images of $\mathrm{OH} *$ chemiluminescence have been obtained at the aforementioned forcing frequencies to provide a useful overall picture of the unsteady flame dynamic behavior under the effect of modulation.

The axisymmetric half flame section at each phase increment is shown at every $90^{\circ}$ phase angle. Figure 8(a) displays phase-synchronized images at $50 \mathrm{~Hz}$. It can be noted that the flame front spreads $\left(180^{\circ}\right)$ and contracts $\left(90^{\circ}\right)$ towards the axis and this formation is more frequently found at conditions closer to a limiting operation as the flame approaches lean blow-off (e.g., $[8,10])$.

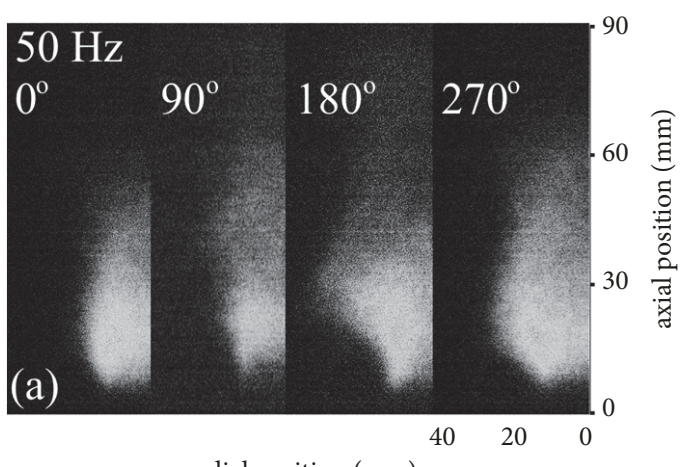

radial position $(\mathrm{mm})$

(a)

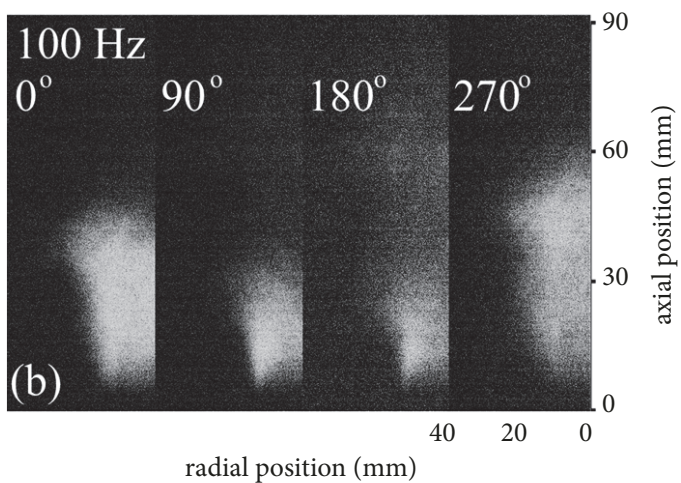

(b)

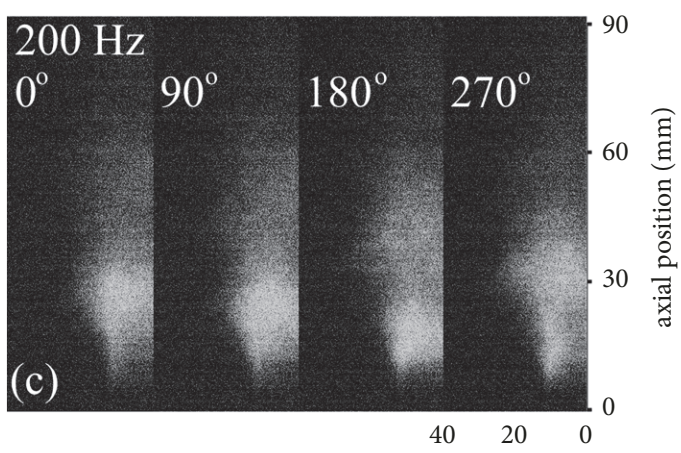

radial position $(\mathrm{mm})$

(c)

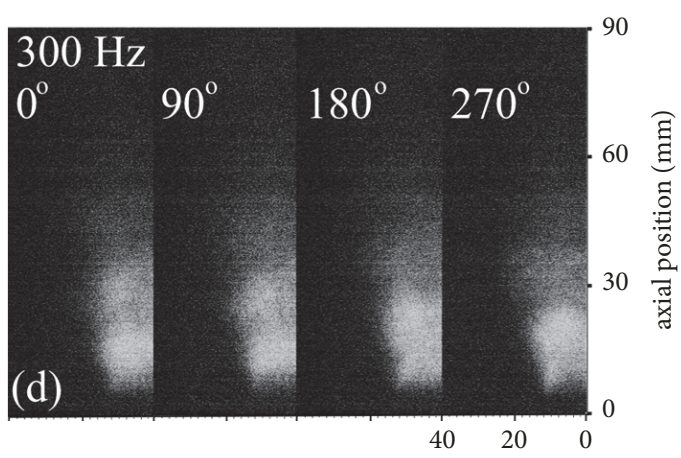

radial position $(\mathrm{mm})$

(d)

FIgURE 8: Phase-synchronized $\mathrm{OH} *$ chemiluminescence images at various forcing frequencies. 
The nonlinear heat release evolution with inlet $\mathrm{u}$ and $\Phi$ variation discussed in Figure 5(a) can be related to a periodic destruction of flame surface area. At the frequency of $100 \mathrm{~Hz}$ the flame front stretched back $\left(0^{\circ}\right)$ and forth $\left(90^{\circ}\right)$, mainly in the axial direction, in response to the inlet oscillation. This behavior was also noticeable at the higher forcing frequencies of 200 and $300 \mathrm{~Hz}$. The near-linear response of the heat release seen in Figure 5(b) was in accord with the apparent synchronization of the flame volume placement with the inlet $\mathrm{u}$ and $\Phi$ signals as also implied from the topologies of Figure 8(b). At $300 \mathrm{~Hz}$ there is evidence of vortex rings rolling along the near wake in line with the disk rim and interacting with the flame front, promoting fuel-air mixing and leading to a shortening of the reacting front extent. The nonlinearity in heat release observed at the $200 \mathrm{~Hz}$ case (Figures 5(c), 5(f), and 5(i)) can be considered as a result of shear layer roll-up and the creation of vortices that are convected along the wake. The topologies of the flame images should also be seen as a result of the variations in the amplitude of the inlet fuel-air mixture profile at the afterbody exit, for the range of the studied frequencies. This should be contrasted to the corresponding velocity perturbation levels, which remain relatively unaffected across the premixer duct and seem to have a lesser influence (Figures 4, 5(a), 5(b), and $5(\mathrm{c})$ ).

\section{Conclusions}

An experimental and computational effort to understand the response of stratified flames subjected to moderate acoustic forcing in a model axisymmetric premixer/bluffbody combustor was presented and discussed. Stratification was introduced through staged fuel-air premixing in a threedisk double-cavity arrangement, while inlet air forcing was applied upstream of the premixer inlet and sustained a modulation of both the velocity and the fuel-air mixture profiles at inlet to the reaction zone.

At the conditions considered here the flame topology variations obtained under forced conditions were significantly influenced by the mixture composition perturbations attained at afterbody exit, which were induced by the harmonic forcing of the premixer inlet velocity. An ultralean flame configuration was chosen for the modulation studies.

The flame was seen to maintain its intensity and extend at lower frequencies due to steeper amplitudes in equivalence ratio oscillations achieved at this forcing level. The higher frequency forcing strengthened the flame by maintaining a flame envelope that was concentrated within the recirculation stabilization region. The adopted LES procedure together with an appropriate choice of combustion and chemistry submodels reproduced significant features of these complicated stratified flames operated under acoustic modulation. Finally, the combined methodology exposed significant effects of acoustic forcing on certain properties of the local and global structure of near limiting stratified flame operation.

\section{Nomenclature}

\section{Roman Symbols}

$\begin{array}{ll}\mathrm{BR}: & \text { Blockage Ratio } \\ \mathrm{C}_{\mathrm{s}}: & \text { Smagorinsky constant } \\ \mathrm{D}_{\mathrm{b}}: & \text { Axisymmetric bluff-body disk diameter } \\ \mathrm{D}_{\mathrm{c}}: & \text { Central air supply tube diameter } \\ \mathrm{F}: & \text { Flow variable } \\ \widetilde{F}: & \text { Favre-weighted resolved scale flow variable } \\ F^{\prime}: & \text { Subgrid scale flow variable } \\ \mathrm{Ka}: & \text { Computed Karlovitz number } \\ \mathrm{k}: & \text { Turbulent kinetic energy } \\ \mathrm{M}_{\mathrm{i}}: & \text { Molecular weight of specie i } \\ \mathrm{m}_{\mathrm{f}}: & \text { Fuel mass flow rate } \\ \mathrm{r}: & \text { Radial location (m) } \\ \mathrm{P}: & \text { Static pressure } \\ \mathrm{Q}: & \text { Heat release } \\ \mathrm{R}_{\mathrm{k}}: & \text { Resolved fraction of the turbulence energy } \\ \mathrm{R}_{\mathrm{u}}: & \text { Universal gas constant } \\ \mathrm{S}_{\mathrm{ij}}: & \text { Resolvable strain tensor } \\ \mathrm{T}: & \text { Time-averaged temperature } \\ \mathrm{t}: & \text { Time } \\ \mathrm{t}_{\mathrm{o}}: & \text { Characteristic flow time } \\ \mathrm{U}: & \text { Time-averaged axial velocity } \\ \mathrm{u}_{0, \text { premixer inlet }}: & \text { Bulk velocity at premixer inlet } \\ \mathrm{u}_{0, \text { blocked }}: & \text { Bulk velocity at afterbody exit plane } \\ \mathrm{x}: & \text { Axial location (m) } \\ \mathrm{x}_{\mathrm{i}}: & \text { Coordinate directions (i=1, 2, 3) } \\ \mathrm{Y}_{\mathrm{k}}: & \text { Gaseous species mass fraction. }\end{array}$

Greek Symbols

$\delta_{\mathrm{ij}}: \quad$ Kronecker delta

$\delta: \quad$ Flame proximity to the lean blow-off limit

$\Delta, \Delta \mathrm{x}, \mathrm{y}, \mathrm{z}_{\mathrm{i}}$ : Characteristic mesh sizes

$\Lambda: \quad$ Extinction parameter

$\mu: \quad$ Dynamic viscosity

$v$ : $\quad$ Kinematic viscosity

$\mu_{\mathrm{t}}, \nu_{\mathrm{t}}: \quad$ sgs eddy-viscosity coefficients

$\rho: \quad$ Density

$\tau_{\mathrm{ch}}: \quad$ Chemical timescale

$\tau_{\mathrm{k}}$ : $\quad$ Kolmogorov timescales

$\tau_{\mathrm{ij}}, \sigma_{\mathrm{ij}}: \quad$ Turbulent stresses

$\Phi: \quad$ Equivalence ratio

$\dot{\omega}: \quad$ Reaction rate.

Superscript

*: Chemiluminescent species.

\section{Subscripts}

b: Burner

c: Central tube

ext: Extinction

f: Fuel

i: Coordinate in tensorial notation 
k: Turbulent kinetic energy

res: Resolved

sgs: Subgrid scale

t: Turbulent conditions.

\section{Data Availability}

The data used to support the findings of this study are available from the corresponding author upon request.

\section{Disclosure}

An excerpt from the above work has been presented in the form of poster in the European Combustion Meeting 2013 (Lund, Sweden).

\section{Conflicts of Interest}

The authors declared no potential conflicts of interest with respect to the research, authorship, and/or publication of this article.

\section{Acknowledgments}

The research was partly supported by the University of Patras Research Council.

\section{References}

[1] D. Bradley, "Fundamentals of Lean Combustion," in Lean Combustion, D. Dunn-Rankin, Ed., pp. 19-54, Academic Press, Elsevier, 1st edition, 2008.

[2] M. S. Sweeney, S. Hochgreb, and R. S. Barlow, "The structure of premixed and stratified low turbulence flames," Combustion and Flame, vol. 158, no. 5, pp. 935-948, 2011.

[3] C. Xiouris and P. Koutmos, "An experimental investigation of the interaction of swirl flow with partially premixed disk stabilized propane flames," Experimental Thermal and Fluid Science, vol. 35, no. 6, pp. 1055-1066, 2011.

[4] B. Higgins, M. Q. McQuay, F. Lacas, J. C. Rolon, N. Darabiha, and S. Candel, "Systematic measurements of $\mathrm{OH}$ chemiluminescence for fuel-lean, high-pressure, premixed, laminar flames," Fuel, vol. 80, no. 1, pp. 67-74, 2001.

[5] P.-H. Renard, D. Thévenin, J. C. Rolon, and S. Candel, "Dynamics of flame/vortex interactions," Progress in Energy and Combustion Science, vol. 26, no. 3, pp. 225-282, 2000.

[6] A. N. Lipatnikov, "Stratified turbulent flames: Recent advances in understanding the influence of mixture inhomogeneities on premixed combustion and modeling challenges," Progress in Energy and Combustion Science, vol. 62, pp. 87-132, 2017.

[7] A. Saurabh and C. O. Paschereit, "Dynamics of premixed swirl flames under the influence of transverse acoustic fluctuations," Combustion and Flame, vol. 182, pp. 298-312, 2017.

[8] S. Chaudhuri and B. M. Cetegen, "Blowoff characteristics of bluff-body stabilized conical premixed flames with upstream spatial mixture gradients and velocity oscillations," Combustion and Flame, vol. 153, no. 4, pp. 616-633, 2008.

[9] K. T. Kim and S. Hochgreb, "The nonlinear heat release response of stratified lean-premixed flames to acoustic velocity oscillations," Combustion and Flame, vol. 158, no. 12, pp. 24822499, 2011.

[10] G. Kuenne, F. Seffrin, F. Fuest et al., "Experimental and numerical analysis of a lean premixed stratified burner using 1D Raman/Rayleigh scattering and large eddy simulation," Combustion and Flame, vol. 159, no. 8, pp. 2669-2689, 2012.

[11] K. T. Kim, J. G. Lee, B. D. Quay, and D. A. Santavicca, "Response of partially premixed flames to acoustic velocity and equivalence ratio perturbations," Combustion and Flame, vol. 157, no. 9, pp. 1731-1744, 2010.

[12] R. Balachandran, B. O. Ayoola, C. F. Kaminski, A. P. Dowling, and E. Mastorakos, "Experimental investigation of the nonlinear response of turbulent premixed flames to imposed inlet velocity oscillations," Combustion and Flame, vol. 143, no. 1-2, pp. 37-55, 2005.

[13] C. Karagiannaki, E. Dogkas, G. Paterakis et al., "A comparison of the characteristics of disk stabilized lean propane flames operated under premixed or stratified inlet mixture conditions," Experimental Thermal and Fluid Science, vol. 59, pp. 264-274, 2014.

[14] K. Souflas, G. Paterakis, and P. Koutmos, "Investigation of diskstabilized propane flames operated under stratified and vitiated inlet mixture conditions," Journal of Energy Engineering, vol. 142, no. 2, 2016.

[15] H. J. Krediet, C. H. Beck, W. Krebs, S. Schimek, C. O. Paschereit, and J. B. W. Kok, "Identification of the flame describing function of a premixed swirl flame from LES," Combustion Science and Technology, vol. 184, no. 7-8, pp. 888-900, 2012.

[16] C. Z. Xiouris and P. Koutmos, "Fluid dynamics modeling of a stratified disk burner in swirl co-flow," Applied Thermal Engineering, vol. 35, no. 1, pp. 60-70, 2012.

[17] O. Colin, F. Ducros, D. Veynante, and T. Poinsot, "A thickened flame model for large eddy simulations of turbulent premixed combustion," Physics of Fluids, vol. 12, no. 7, pp. 1843-1863, 2000.

[18] G. Wang, M. Boileau, and D. Veynante, "Implementation of a dynamic thickened flame model for large eddy simulations of turbulent premixed combustion," Combustion and Flame, vol. 158, no. 11, pp. 2199-2213, 2011.

[19] P. Koutmos and K. Souflas, "A study of slender bluff-body reacting wakes formed by concurrent or countercurrent fuel injection," Combustion Science and Technology, vol. 184, no. 9, pp. 1343-1365, 2012.

[20] C. J. Dasch, "One-dimensional tomography: A comparison of abel, onion-peeling, and filtered backprojection methods," Applied Optics, vol. 31, no. 8, pp. 1146-1152, 1992.

[21] Z. Han and S. Hochgreb, "The response of stratified swirling flames to acoustic forcing: Experiments and comparison to model," Proceedings of the Combustion Institute, vol. 35, no. 3, pp. 3309-3315, 2015. 


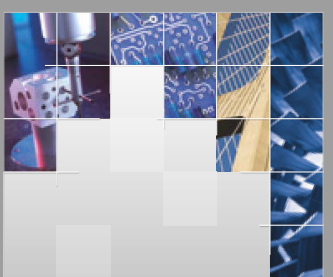

\section{Enfincering}
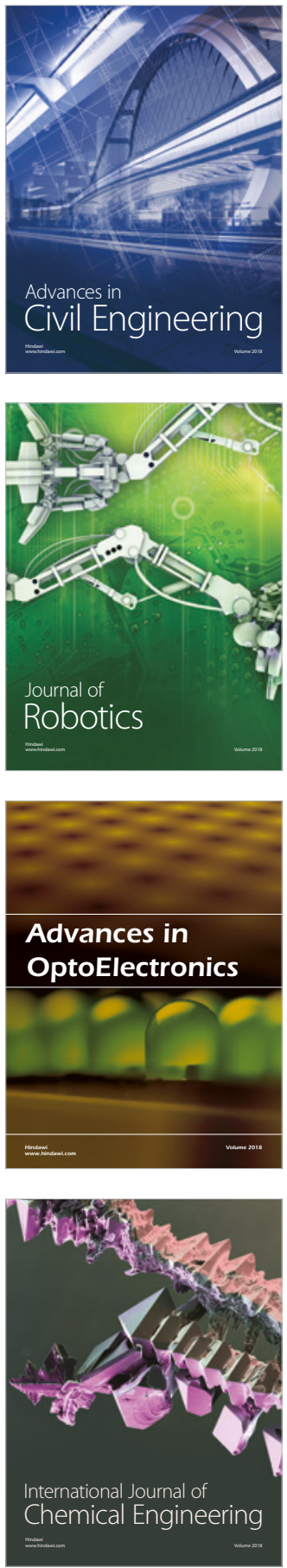

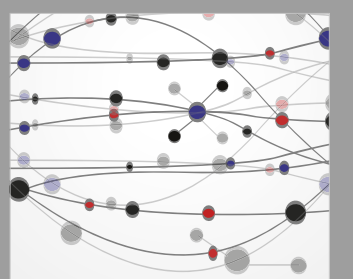

\section{Rotating \\ Machinery}

The Scientific World Journal

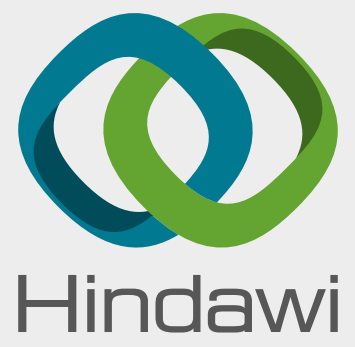

Submit your manuscripts at

www.hindawi.com
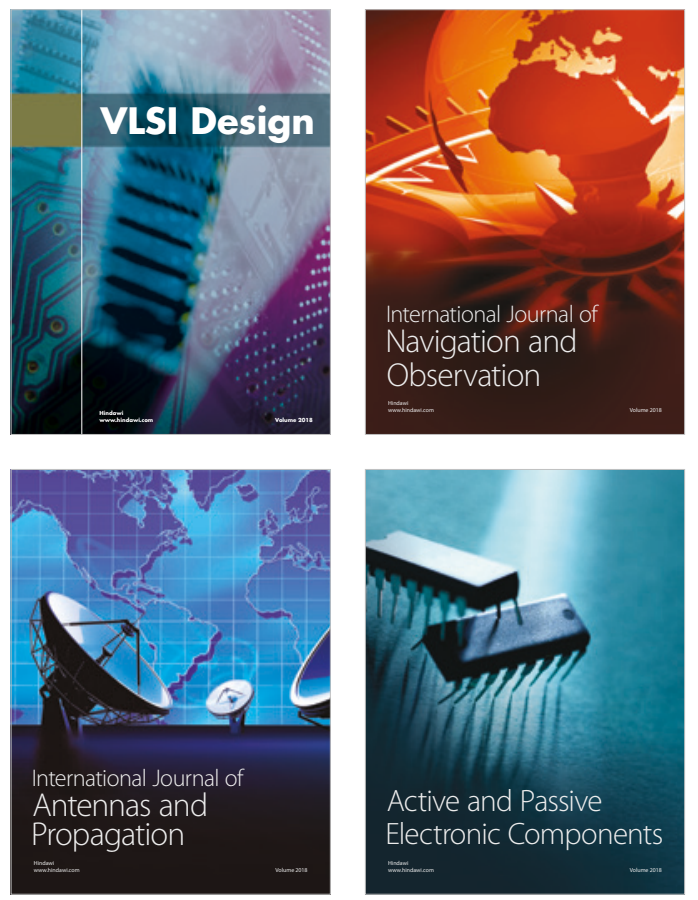
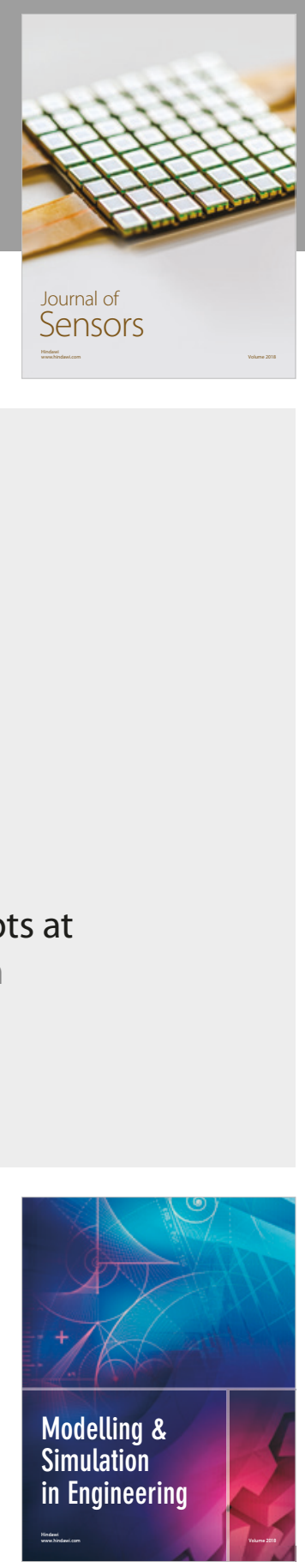

\section{Advances \\ Multimedia}
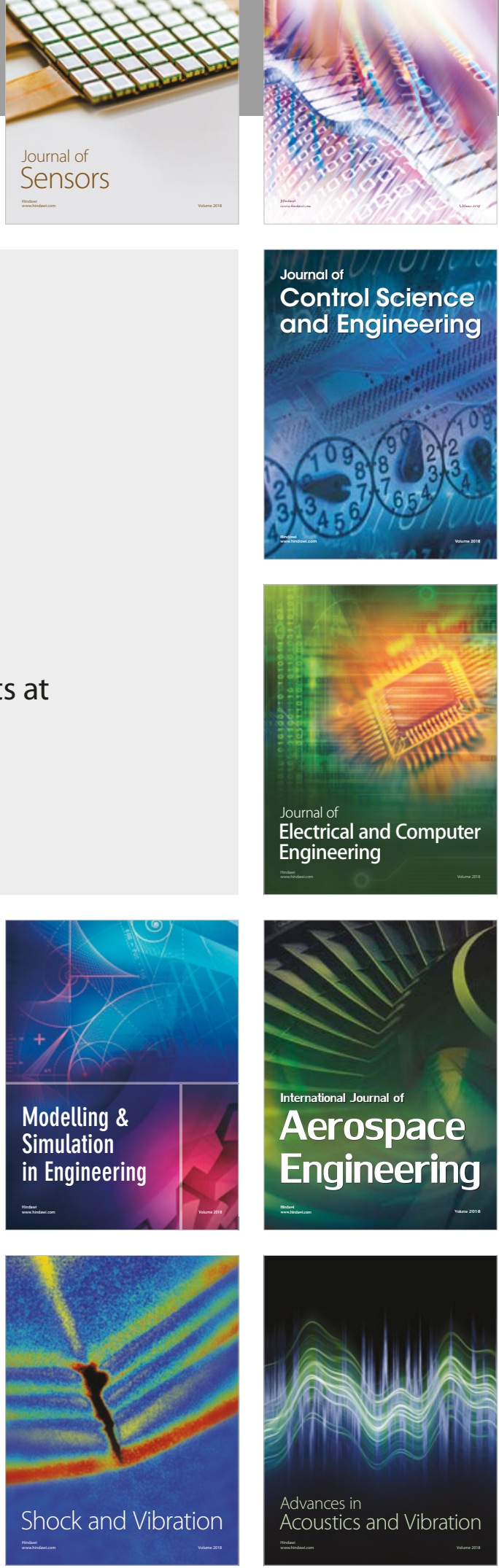